\title{
The battle between biological and synthetic meshes in ventral hernia repair
}

\author{
A. Montgomery
}

Received: 23 December 2012/ Accepted: 3 January 2013 / Published online: 13 January 2013

(C) Springer-Verlag France 2013

Introduction of meshes for reinforcement has revolutionized the results of abdominal wall reconstructive surgery. Patients, even with former hopeless abdominal wall conditions, can be offered a new life gained from these developments. There is though a constant introduction of new "tailored" mesh products on the market, suggested to be used in different clinical settings and in different positions in the abdominal wall, hopefully with the aim to improve the results even further. The huge problem is the lack of evidence on when, where or even ever a specific mesh is to be used.

A hot discussion at the moment is the indication on when to use a synthetic or biological mesh (BM). The total numbers of meshes that are exposed to the surgeons are enormous. Another huge problem is that there are subgroups within each mesh group that act totally different form others making it impossible to recommend one or the other type in a specific patient.

In this issue of hernia, a total of eleven papers have been gathered concentrating mainly on complicated hernia situations, the use of different techniques, and different meshes for ventral hernia repair (VHR). Below you will find different arguments on pros and cons on biologic and synthetic meshes referring to the actual literature and by commenting the papers presented in this issue of Hernia with the aim to balance the discussion.

\footnotetext{
A. Montgomery $(\bowtie)$

Department of Surgery, Institution of Clinical Science,

Skåne University Hospital, Lund University,

20502 Malmö, Sweden

e-mail: Agneta.montgomery@skane.se
}

\section{The concept of biologic meshes}

The ultimate goal of biological meshes (BM) is to support the abdominal wall until new healthy collagen tissue, produced by the patient, has replaced the mesh and resulted in a stable abdominal wall.

Biological meshes are usually harvested form collagenrich tissues from cadavers or animals that are made acellular with the purpose to provide a scaffold, also rich of growth factors, for native regeneration of collagen tissue. A lot of different meshes with different properties have been introduced on the market for clinical use. Almost all evidences for the success of BM are based on studies made on fast-growing small healthy animals [1].

Biological integration of the mesh is important and desirable. This will ultimately take place by the ingrowth of mononuclear cells followed by new blood vessel proliferation and fibroblasts forming new collagen within the mesh. To make this remodeling process happen is a huge challenge. All meshes will introduce a foreign body response that needs to be balanced in order to result in normal wound healing. Chemicals used for making the meshes acellular can remain within the mesh causing both toxic and inflammatory reactions in the patient.

There are many steps that can fail. One end result might be an early degradation or absorption of the mesh by collagenase. Collagen cross-linking of different types has been introduced to prolong mesh lifespan. Some animal data have suggested that there is a lack of integration/remodeling of the crosslinked mesh (especially in the center of the defect) that could ultimately result in a scar plate and encapsulation of the mesh comparable to the process described in some situations for the synthetic ePTFE mesh. Non-cross-linked meshes seem to exhibit more favorable remodeling characteristics to the price of faster degradation. The supplemental cross-linking has 
been addressed in a recently published review of 21 published animal studies, concluding that supplemental cross-linking of collagens has not been shown to adversely affect the strength of the implant [2].

The whole philosophy of BM is based on the synthesis of new collagen. What about the quality of this collagen? Do we have any results on this in humans? Most patients who would develop a ventral hernia do have several risk factors for having an impaired collagen synthesis.

Thus, the biologics are not one entity of meshes working all the same in different situations. This is also demonstrated by Novitsky and Rosen [1] reporting on all the different types of biological meshes and their different properties. Meshes working differently in different positions have also been illustrated by Stadlhuber et al. [3] who reported of several cases of esophageal stenosis/erosion from the use of both synthetic and biological meshes for the reinforcement of the crural closure during hiatal hernia repair. In this issue of Hernia, however, Powell et al. [4] illustrate that another group of meshes, namely the "synthetic remodeling meshes" seem to work without complications in the early phase in 70 patients who underwent hiatal repair. The same "synthetic remodeling mesh" (polyglycolic acid/trimethylene carbonate) has been used in a pilot study on inguinal hernia repair by Symeonidis et al. [5] also reported on in this issue of Hernia. The results are here discouraging showing a $38 \%$ recurrence rate after a mean follow-up of 2 years concluding skepticism about the generalized use of an absorbable mesh in this setting. The publications on this fairly new group of meshes are restricted.

\section{Costs of meshes}

Another important issue is the cost of meshes. There is today a huge price difference between the synthetic and biological meshes. The use of BMs in uncomplicated situations or in situations where they are not proven to act in favor of the synthetic meshes cannot be justified due to costs. In a survey including 230 surgeons performing VHR, Harth et al. [6] report in this issue of Hernia on the use and indication for BMs in the United States. Indications based on wound classification varied and lacked consensus. The most reported influences for the use included personal experience, literature, and availability. It was concluded that there was an inappropriate overuse of these expensive materials.

\section{Different types of synthetic meshes and surgical technique}

There are different properties also for synthetic meshes. Polypropylene, polyester, and ePTFE are the most commonly used, and they also exhibit different properties. The development of new type of synthetic meshes is also extensive and fast. The foreign body reaction is minimized by the change from heavy weight "standard" pore meshes to low weight "mega" pore meshes in order to reduce the fibrotic scar tissue formation and shrinkage around the mesh. Professor Klinge and the Aachen group have performed a huge amount of research in this field also ranging the meshes due to different properties [7]. The ePTFE mesh has totally different characteristics. It has very good antiadhesive capacity but commonly needs to be removed when infection or fistulas occur.

Another "confounding" and important factor is the surgical performance of the surgeon. It is not very often discussed. It has been demonstrated by Arvidsson et al. [8] in a randomized controlled trial on inguinal hernia surgery that there is a correlation between surgical performance and recurrence rate.

\section{Location of mesh}

We also have to take into consideration where to put the mesh ideally. There are several options possible: onlay, sublay (retromuscular, pre- or intraperitoneal, or intermuscular when placed laterally), or inlay. The retromuscular position seems to be the most commonly used and safe position [9].

Synthetic meshes are usually designed to be positioned outside the abdominal cavity unless a special coating has been applied for intra-abdominal use. These restrictions do not seem to exist for BM. An intra-abdominal placement is frequently reported as in the paper of Diaz-Siso et al. and in the paper of Rosen et al. in this issue of Hernia [10, 11]. Hypothetically, the biological mesh is a matrix for cellular ingrowth and neovascularization from both surfaces of the mesh. How would a mesh being positioned intra-abdominally know where to recruit its blood supply from? By logic it would be from both the peritoneal surface and the intestines and omentum on the opposite side. Probably, this might not be an issue unless there is an infectious complication or a fistula formation. Anecdotal case reports and data from own personal communication support this is happening. In operating, a few patients with a frozen abdomen together with an entero-cutaneous fistula having a biologic mesh in place resulted in an en-bloc resection of the mesh together with the underlying small intestine. The mesh was totally incorporated with the wall of the small intestines making it impossible to identify a plane for dissection. Therefore, it seems that the best place for a biological mesh is probably also the retromuscular compartment, possibly because of the contact of the mesh with highly 
vascularized muscular tissue. This was also suggested by Rosen et al. [11] in this issue of Hernia.

New innovative techniques, with the aim to reduce complications in difficult cases, are often presented as case reports as by $\mathrm{Wu}$ et al. [12] in this issue of Hernia. A technique for bridging a large abdominal wall defect, using a combination of an inlay BM covered by an autogenously derived pedicle from a demucosalized small intestinal sheet on to of the mesh that is finally covered by a skin graft, is described with a successful result up to 8 months.

\section{Hernia grading system}

The purpose of making a grading scale could be multifactorial. An optimal grading scale should give a valid indication on which technique in combination with which mesh to be used in different clinical settings. Concerning individual patients in need of VHR, it would be to choose the optimal surgical technique, the optimal mesh to receive the best result with minimal trauma, minimal risk of complications, and sequelae. This is often referred to as "tailored surgery."

There is a problem in making a grading scale since there are several factors that you have to take into account. You have the patient's global risk factors including co-morbidity that could have a major impact on the end result. You have the hernia related factors: location, hernia gap, hernia sac size, and content. You have the contamination factors: skin contamination/infection, stomas, deep abdominal infections, wound dehiscence, ischemic bowel, bowel surgery, loss of domain etc. The degree of contamination has already a well-established grading system: Centers for Disease Control (CDC) wound classification system. It is widely used and accepted. It is graded into four groups (clean, clean-contaminated, contaminated, and dirty). The scenarios could be numerous when mixing the above factors. It is delicate to anticipate how the magnitude of the individual factors would interact in choosing a specific technique and/or mesh.

The massive launch, followed by wide indications set for the use of BM in VHR, has resulted in a wide use of BMs on the American continent after the publication of a new grading system including recommendations for VHR by the Ventral Hernia Working Group (VHWG) [13]. This VHWG grading scale is a non-validated instrument that was developed through a consensus discussion of eight surgeons from different parts of the United States, having an extensive experience in VHR. It was developed with the purpose to grade the risk of surgical site occurrence (SSO) during VHR.

The scale is presented as Grade 1-4, Table 1. It is based on a strange mixture of co-morbidities and degree of contamination. The co-morbidities are global factors for all patients that could have a tremendous impact on the outcome for both non-contaminated and contaminated patients. The extent of the co-morbidities, which are not defined, could also be of great importance. Having had a former currently healed wound infection that would interact with the end result is also not universally accepted. Most surgeons would regard this condition as being a clean operation without an increased risk for SSO. Hernia related factors like defect size, location, loss of domain, recurrent hernia with present mesh, and the use of mesh for bridging a defect (vs. augmenting the defect i.e. fascia closure in addition to mesh placement) are factors that are of major importance for the complexity of the surgery and the outcome that have not been taken into account in this grading system.

\section{Recommendations}

Apart from the grading system, the recommendations for use of BM in VHR are included in the VHWG publication [12]. Surgeons like to follow recommendations in their surgical practice. There is a huge lack of recommendations in the field of VHR. The reason for this is the lack of scientific evidence. The European Hernia Society (EHS) has identified the problem since long, but has decided that the level of evidence is too low to publish guidelines like for inguinal hernia surgery [14]. Recommendations should not only be based on one single outcome like in VHWG recommendations. The most important outcome measurements should be discussed like, for example, SSO, recurrence, pain, and quality of life.

The authors of the VHWG give the recommendation based on either opinion and/or evidence from the literature. The reported evidence is based mainly on old low-quality publications summarized in Table 1. The VHWG grading attempt and recommendations are embraced by surgeons, lawyers, and the industry, all having their own rationale. The price will be paid by the patient if recommendations result in an individual disaster. We agree that also socioeconomic aspects need to be taken into account, especially when discussing the role of BM in VHR in complex cases.

The intention in suggesting a grading system and recommendation on what mesh to use is of cause very attractive, but do we really have the evidence to come to the conclusions and recommendations stated by the VHWG group? I believe honestly the answer is no. Before introducing a new grading system, it has to be validated. The VHWG grading system has been questioned by one of the authors in a recent paper using the grading scale retrospectively in 299 patients analyzing the accuracy of the scale to predict SSOs [15]. A modification into a 3-grade 
Table 1 Ventral hernia grading system, recommendation of repair material, and level of evidence for recommendation (Oxford classification system) reported from the Ventral Hernia Working Group (VHWG) [4]

\begin{tabular}{|c|c|c|c|}
\hline & Inclusions & Recommendations & Literature presented as evidence \\
\hline $\begin{array}{l}\text { Grade } 1 \\
\text { Low risk }\end{array}$ & $\begin{array}{l}\text { Low risk of } \\
\text { complications } \\
\text { No history of } \\
\text { wound infection }\end{array}$ & $\begin{array}{l}\text { Choice of repair material by surgeons preference } \\
\text { and patient factors }\end{array}$ & VHWG opinion only \\
\hline $\begin{array}{l}\text { Grade } 2 \\
\text { Co-morbid }\end{array}$ & $\begin{array}{l}\text { Smoker } \\
\text { Obese } \\
\text { Diabetic } \\
\text { Immunosuppressed } \\
\text { COPD }\end{array}$ & $\begin{array}{l}\text { Increased risk of surgical site occurrence suggests } \\
\text { additive risk of permanent synthetic repair } \\
\text { material, and potential advantage for appropriate } \\
\text { biologic reinforcement }\end{array}$ & $\begin{array}{l}\text { VHWG opinion and } 4 \text { papers on risk factors for } \\
\text { infection (all papers on synthetic meshes) } \\
\text { 1. } 2003 \text {; RS-open mesh repair } 487 \text { patients: } 4.4 \% \\
\text { SSI and } 15 \% \text { recurrences. } \\
\text { 2. } 2005 \text {; RS multicentre-1505 VHR: } 5 \% \text { SSI } \\
\text { 3. 2006; RS-inguinal hernia repair without mesh } \\
\text { 4. 2001; RS-121 sub-facial mesh (PP, polyester } \\
\text { and ePTFE). } 7 \% \text { SSI. } 3 \text { mesh removals-all } \\
\text { ePTFE }\end{array}$ \\
\hline $\begin{array}{l}\text { Grade } 3 \\
\text { Potentially } \\
\text { contaminated }\end{array}$ & $\begin{array}{l}\text { Previous wound } \\
\text { infection } \\
\text { Stoma present } \\
\text { Violation of the } \\
\text { gastrointestinal } \\
\text { tract }\end{array}$ & $\begin{array}{l}\text { Permanent synthetic repair material generally not } \\
\text { recommended; potential advantage to biologic } \\
\text { repair material }\end{array}$ & $\begin{array}{l}4 \text { papers: } 2 \text { biologics and } 2 \text { synthetic } \\
\text { 1. 2006; RS-dermal matrix, } 75 \text { patients CC and } \\
\text { CD. } 33 \% \text { SSI ( } 15 \% \text { non-operated, } 19 \% \\
\text { reoperation), } 7 \% \text { mesh removals } \\
\text { 2. } 1989 \text {; RS - synthetic, } 80 \text { VHR: } 16 \% \text { SSI ( } 5 \\
\text { patients had previous SSI) } \\
\text { 3. } 1989 \text {; RS and review, synthetic to bridge in } \\
\text { emergency setting with bowel edema, over all } \\
\text { complications } 55 \% \text {. } \\
\text { 4. } 2006 \text {; RS-dermal matrix, } 29 \text { patients with } \\
\text { either SSI or poor skin coverage. } 45 \% \text { SSO and } \\
\text { 10\% recurrences in } 6 \text { months }\end{array}$ \\
\hline $\begin{array}{l}\text { Grade } 4 \\
\text { Infected }\end{array}$ & $\begin{array}{l}\text { Infected mesh } \\
\text { Septic dehiscence }\end{array}$ & $\begin{array}{l}\text { Permanent synthetic repair material not } \\
\text { recommended; biologic repair material should } \\
\text { be considered }\end{array}$ & $\begin{array}{l}\text { 8 papers: } 3(\mathrm{Nr} 1,3,4) \text { are the same as above and } 5 \\
\text { are new } \\
\text { 1. } 2007 \text {; RS_ePTFE, } 22 \text { mesh infections (15 lap } \\
\text { and } 7 \text { open), } 16 \text { total and } 6 \text { partial mesh } \\
\text { excisions. } \\
\text { 2. } 2007 \text {; RS-dermal matrix, } 67 \text { patients with } \\
\text { contamination; mesh above or beneath the fascia } \\
\text { or as inlay. } 23 \% \text { SSI, } 3 \% \text { mesh removals, } 18 \% \\
\text { recurrences within } 10 \text { months } \\
\text { 3. } 2003 \text {; RS-late treatment for } 11 \text { patients with } \\
\text { chronic drainage or EC fistulas with mesh } \\
\text { removal } \\
\text { 4. } 2007 \text { (patients included } 1988-1998 \text { ); RS- } \\
\text { synthetic meshes (PP, polyester and polyglactin) } \\
\text { for wound dehiscence, } 18 \text { patients. All had } \\
\text { complications either SSI, intra-abdominal } \\
\text { abscess or EC fistula. } 44 \% \text { mesh removals, } 33 \% \\
\text { mortality. } \\
\text { 5. } 1981 \text {; RS-PP, } 31 \text { patients, } 29 \text { heavily } \\
\text { contaminated wounds (fascitis and intra- } \\
\text { abdominal abscesses) massive bowel distension, } \\
\text { extensive tissue loss. } 7 \text { died from primary illness. } \\
\text { Mesh used for abdominal wall integrity. Mesh } \\
\text { complications }\end{array}$ \\
\hline
\end{tabular}

system was suggested that improved the accuracy to predict SSOs according to Table 2.

Stratification of risks of SSO after VHR remains a challenge. The assumption that a previous wound infection would result in an increased risk for a surgical site infection (SSI) has been questioned. In 146 patients prospectively registered in a database, the SSI did not differ between those with or without a history of wound infection [16]. 


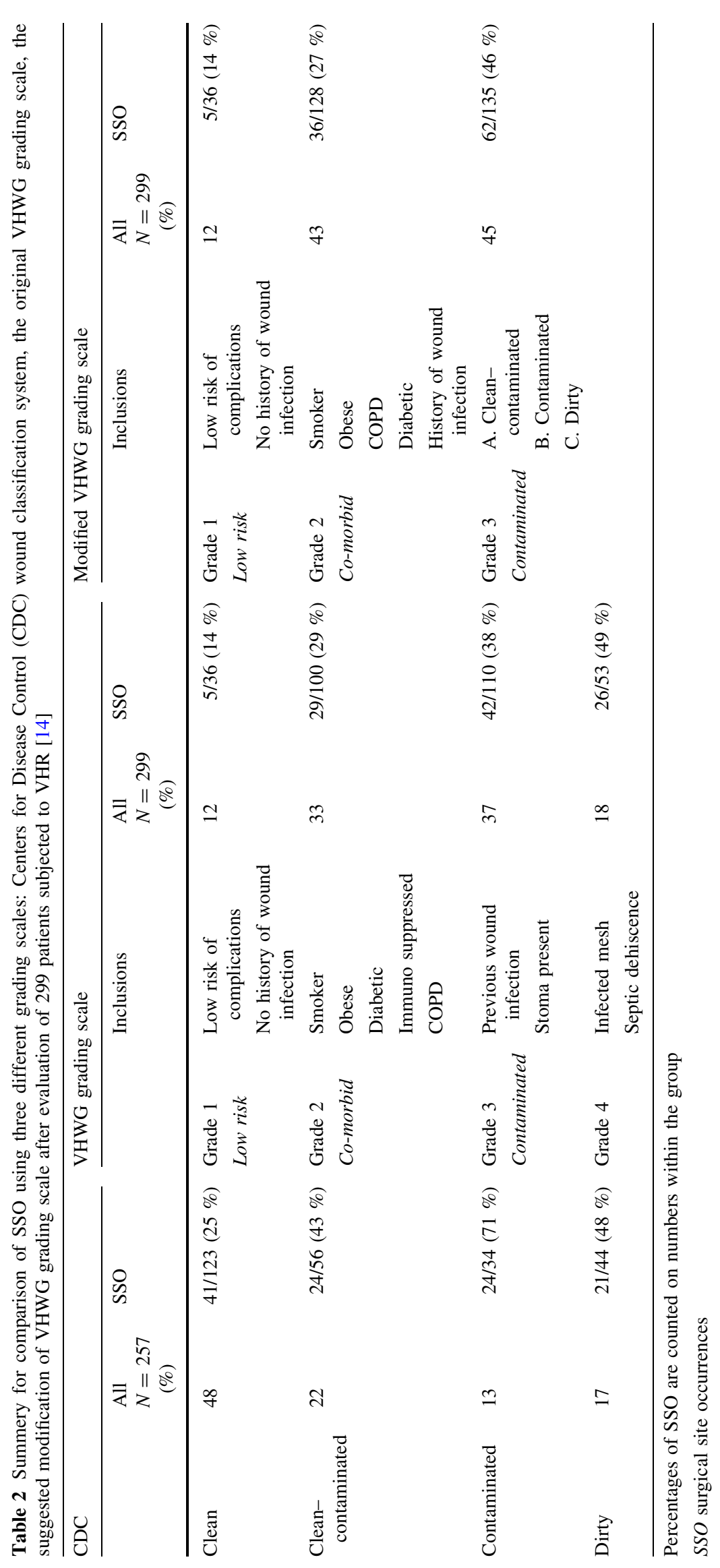


In a study by Krpata et al., 88 patients with a grade 2 (VHWG), having a retromuscular synthetic mesh, resulted in only $16 \%$ SSOs and no mesh removals. It was concluded that synthetic meshes are safe in grade 2 patients [17]. In a large study by Choi et al. from the National Surgical Quality Improvement Program (NSQIP) registry in the United States, including 33,832 patients demonstrated a higher risk for SSO in clean-contaminated and contaminated compared to clean cases using a mesh. There was also an increased risk of SSI in clean-contaminated cases after the use of mesh versus no mesh as anticipated [18].

\section{Clinical outcome of biological meshes}

The literature is sparse on level 1-2 evidence concerning clinical outcome for BMs. No randomized studies comparing biologic to each other or to synthetic meshes exist in VHR, except preliminary data from the European multicenter LAPSIS trial comparing synthetic to BM in open and laparoscopic VHR under clean circumstances [19].

Three systematic reviews on the clinical use of BMs have been identified and published during 2012 [20-22]. The most recent and well-performed study by Bellows et al. included 60 studies (most retrospective) with a total of 1,241 patients. Contamination (grade 3) using the VHWG definition was seen in $48 \%$, and at least, one complication was seen in $87 \%$ of repairs. SSI was seen in $17 \%$ and seromas in $12 \%$. Mean follow-up was 14 months and resulted in a $15 \%$ recurrence rate. Mortality was $4 \%$. The overall incidence of SSO ranged from 6 to $83 \%$ between different meshes [20]. In the study by Smart et al, five prospective studies were included and they concluded that mesh exhibits a low recurrence rate in clean fields, but the recurrence rate in infected field was $39 \%$ [22].

In this issue of Hernia, a new review is presented by Primus and Harris [23]. This is a most interesting paper questioning both the grounds for the FDA approval of BMs and for its use in contaminated fields. The xenograft meshes are regarded as medical devices just like general surgical meshes and are regarded as "substantially equivalent" to what is already on the market by a clearance process. The allografts are treated differently and are regarded as human tissue for transplantation (not regarded as medical devices). The allografts did not acquire FDA approval to be used as a surgical mesh on the market. A systematic review was performed on already identified review articles up to March 2011 concluding that the use of BM for VHR under contaminated conditions is, as claimed, not better than synthetic meshes under the same conditions. The authors also claim that using a BM in contaminated situations is being done outside the original intended use. The authors are now in process of conducting a multisite, FDA-supported randomized controlled trial, to compare synthetic versus BM for repair of complex VHRs in a setting of wound contamination regarding recurrences and costs. This initiative sounds like beloved music in the ears and we do hope that it will become true.

The recently published RICH study by Itani et al. [24] is a well-performed prospective multicenter study from 12 institutions across United States. The non-cross-linked porcine dermal matrix mesh Strattice ${ }^{\circledR}$ was used in a retromuscular position (Rives-Stoppa) aiming to restore the midline. A total of 80 patients with a hernia defect of $\geq 9 \mathrm{~cm}^{2}(3 \times 3 \mathrm{~cm})$ classified as clean-contaminated (49\%), contaminated (49\%), and dirty (2\%) were included, and 60 patients were followed for 2 years. Facial closure was not achieved in $19 \%$ despite the use of component separation. After 2 years, $66 \%$ of the patients had experienced an SSO. Wound infections were reported in $24(30 \%)$ patients out of which 11 had late occasions (caused by 5 abscesses, 3 chronic draining sinuses, and 3 late cellulites and persistent wound drainage). Hernia recurrence rate was based on clinical assessment and was $19 \%$ at 1 year and $28 \%$ at 2 years. This percentage is though counted on the intention-to-treat group of 80 patients. Only 60 patients remained after 2 years possible for clinical investigation making the actual recurrence rate $37 \%$. The recurrence rate after bridging at 24 months, with or without applying a component separation, was as high as $44 \%$.

The published results on BMs already give us a strong indication that the collagen regeneration (after use of a non-cross-linked material) does not work sufficiently enough to give an abdominal support for life when the mesh is used for bridging.

\section{Clinical outcome of synthetic meshes}

Synthetic meshes have been used widely in large quantities through decades. The unfavorable results described by the VHWG group do no correlate to the everyday reality seen by most expert centers in Europe using a synthetic mesh as a routine to solve also the most complicated cases, even in cases of clean-contamination with severe comorbidity. The key to success is choosing the right mesh to be put in the right position for different clinical scenarios in a tailored way.

A lot of the bad results described where synthetic meshes need to be removed refer to the ePTFE meshes. In addition, most polyester materials used are multifilament meshes that can potentially harvest bacteria. The polypropylene meshes are made of monofilaments and are the most 
widely used with its properties of excellent ingrowth when used in the retromuscular space referred to as the RivesStoppa technique. Whether the new megaporous meshes are sufficiently strong in case of bridging a defect remains to be shown.

A SSI, also including mesh infections, can be treated successfully using a vacuum-assisted closure (VAC) technique described by Berrevoet et al. [25] in this issue of Hernia. In particular, the megaporous meshes are causing excellent granulation between the mesh filaments. This technique is frequently used in a lot of centers and is a great success for wound healing also in complicated infected patients. The VAC systems are under a continuous development, and competition between companies has made the price for treatment reasonable.

Another tricky situation is the acute incarcerated hernias. In this issue of Hernia, Bessa and Raazek [26] from Egypt report on a prospective study including 80 patients with incarcerated ventral (primary and secondary) hernias. The defect $(>3 \mathrm{~cm})$ was all closed transversally covered with an onlay polypropylene mesh. A small bowel resection was performed in $22 \%$. A meticulous clinical followup was performed reviling $12 \%$ short time SSI, one mesh explantation due to chronic sinus, and one recurrence was reported in a median of 50-month follow-up. This demonstrates that a synthetic mesh can be safely be used in this acute setting. One tool to decrease the risk of wound infection is the laparoscopic approach in VHR. In a Cochrane review comparing laparoscopic to open surgery, 10 randomized controlled studies (RTC) were included with a total number of 880 patients. Apart from the benefit in decreasing SSI, the laparoscopic technique looks comparable to open surgery in the short-term, but there is no evidence yet to draw any conclusions on long-term efficacy [27].

The specific group of patients operated in a dirty setting deserves specific attention. Most surgeons agree that in those very sick patients (peritonitis, catabolic state, multiple organ failure...), the development of a huge delayed ventral hernia due to open abdomen/laparostomy and subsequent skin grafting in itself is a very serious situation with high morbidity and mortality. On the other hand, it is known that a BM is also unlikely to perform well in case of a heavy (continuous) bacterial load. In these cases, it has been proposed to decrease the bioburden and control the source of sepsis by repetitive reentry and abdominal lavage in order to downgrade the wound to a grade of contamination, before using a mesh for abdominal wall closure, if any [28]. Although the final closure of the abdomen is likely to be a good indication for a BM, some authors have advocated the use of (megaporous) polypropylene mesh in those circumstances with acceptable results. Possibly, the combination of both biological and synthetic meshes is another way to explore, as suggested in this issue of Hernia by Morris and LeBlanc [29], although the degree of contamination was unclear in this study. Further comparative studies are awaited.

To make an augmentation of the abdominal wall without using a mesh has been demonstrated in this issue of Hernia by Espinosa-de-los-Monteros et al. [30] with a successful result. A "double" closure of the midline and a component separation technique (CST) in a small number of large complex abdominal wall hernias resulting in $30 \%$ SSOs and one recurrence up to median 2 years are reported. Anyhow a lot of patients in need of VHR do have several risk factors for low-quality collagen that would need a mesh for augmentation. Some patients do also develop a new hernia at the location of the CST.

\section{Registers}

We do not have evidence enough to discuss on what mesh to use, what technique to use and in which clinical scenario. We need to gather more information. A patientbased register is the most ideal form to bring more information on the results on inhomogeneous patient cohorts. You will gather a large number of patients in a short time not only in specialist centers. Bad techniques and meshes can be sorted out from the market much earlier.

The Danish Ventral Hernia Database is the most wellestablished ventral hernia register. In one study, it was concluded that reoperation rate for recurrence underestimates the overall risk of a recurrence by fivefold for incisional hernias [31]. There is also a register in Sweden and in Germany with no formal publications yet. EHS did try to lounge a register for biological meshes some years ago in order to gather information on the results from the introduction of the BMs on the market in Europe [32]. This did however not work despite huge efforts, and this is currently not being used. In Italy, the Italian Biological Prosthesis Work-Group (IBPWG) was established and has published its results from 264 biological implants in Italy [33]. A scoring system was developed, with the purpose to help the surgeon to choose between cross-linked and non-crosslinked BM.

The EHS has recently lounged a ventral hernia database named "EuraHS" [34]. This is a register developed by hernia specialists form several countries in Europe. There are strict definitions of all variables (including patient, hernia and mesh characteristics as well as different degrees of contamination according to the CDC classification) that are entered making the registration variables possible to compare. The follow-up also includes simple questions on quality of life. All units are encouraged to join the register in order to get control of your own results. You can join as 
a single surgeon or as a group locally or nationwide. The database can also be used for scientific studies. The database can be reached on the web site [9].

\section{In summary}

So who is the winner of this battle? So far the tussle is still going on. There is though insufficient level of high-quality evidence on the value of BMs for VHR so far. Until more data are available, the best current indication for biological meshes is probably the contaminated setting, on the condition that the bacterial load has been reduced as much as possible before implanting the mesh, preferably in the retromuscular positioning with a maximal attempt for fascia closure on top of the mesh.

More evidence is needed in order to sort out situations where these expensive meshes might be justified. Maybe this situation will solve itself by further developments on the mesh market. The ideal mesh is not here yet, and possible modifications in cross-linking technology or tissue engineering-based technologies might guide us in the (near) future. Waiting for randomized control studies alone will not be the solution due to difficulties in defining homogenous criteria's for inclusion. Patients are too few to meet the statistical need for an adequate power in such studies even though an attempt seems to be in process. Faster results and dependable information will be available by using a uniform database for universal registration.

\section{References}

1. Novitsky YW, Rosen MJ (2012) The biology of biologics: basic science and clinical concepts. Plast Reconstr Surg 130(5 Suppl 2):9S-17S

2. Smart NJ, Daniels IR, Marquez S (2012) Supplemental crosslinking in tissue-based surgical implants for abdominal wall repair. Int J Surg 10(9):436-442

3. Stadlhuber RJ, Sherif AE, Mittal SK, Fitzgibbons RJ Jr, Michael Brunt L, Hunter JG, Demeester TR, Swanstrom LL, Daniel Smith C, Filipi CJ (2009) Mesh complications after prosthetic reinforcement of hiatal closure: a 28 -case series. Surg Endosc 23(6):1219-1226

4. Powell BS, Wandrey D, Voeller GR (2012) A technique for placement of bioabsorbable prosthesis with fibrin glue fixation for reinforcement of crural closure during hiatal hernia repair. Hernia. doi:10.1007/s10029-012-0915-4

5. Symeonidis D, Ethimiou M, Koukoulis G, Athanasiou E, Mamaloudis I, Tzovaras G (2012) Open inguinal hernia repair with the use of polyglycolic acid/trimethylene carbonate absorbable mesh: a critical update of long term results. Hernia. doi:10.1007/ s10029-012-1016-0

6. Harth KC, Krpata DM, Chawla A, Blatnik JA, Halaweish I, Rosen MJ (2012) Biologic mesh use practice patterns in abdominal wall reconstruction: a lack of consensus among surgeons. Hernia. doi:10.1007/s10029-012-1029-8
7. Klinge U, Klosterhalfen B (2012) Modified classification of surgical meshes for hernia repair based on the analyses of 1,000 explanted meshes. Hernia 16(3):251-258

8. Arvidsson D, Berndsen FH, Larsson LG, Leijonmarck CE, Rimbäck G, Rudberg C, Smedberg S, Spangen L, Montgomery A (2005) Randomized clinical trial comparing 5-year recurrence rate after laparoscopic versus Shouldice repair of primary inguinal hernia. Br J Surg 92(9):1085-1091

9. European register of abdominal wall hernia. http://www.eurahs.e

10. Diaz-Siso JR, Bueno AM, Pomahac B (2012) Abdominal wall reconstruction using a non-cross-linked porcine dermal scaffold: a follow-up study. Hernia. doi:10.1007/s10029-012-0927-0

11. Rosen M, DeNoto G, Itani KMF, Butler CE, Vargo D, Smiell J, Rutan R (2012) Evaluation of surgical outcomes of retro-rectus versus intraperitoneal reinforcement with bio-prosthetic mesh for contaminated ventral hernia repair. Hernia. doi:10.1007/s10029012-0909-2

12. Wu Y, Ren J, Liu S, Han G, Zhao Y, Li J (2013) Abdominal wall reconstruction by combination use of biological mesh and autogenous pedicled demucosalized small sheet: a case report. Hernia. doi:10.1007/s10029-012-0965-7

13. Breuing K, Butler CE, Ferzoco S, Franz M, Hultman CS, Kilbridge JF, Rosen M, Silverman RP, Vargo D, Ventral Hernia Working Group (2010) Incisional ventral hernias: review of the literature and recommendations regarding the grading and technique of repair. Surgery 148(3):544-558

14. Simons MP, Aufenacker T, Bay-Nielsen M, Bouillot JL, Campanelli G, Conze J, de Lange D, Fortelny R, Heikkinen T, Kingsnorth A, Kukleta J, Morales-Conde S, Nordin P, Schumpelick V, Smedberg S, Smietanski M, Weber G, Miserez M (2009) European Hernia Society guidelines on the treatment of inguinal hernia in adult patients. Hernia 13(4):343-403

15. Kanters AE, Krpata DM, Blatnik JA, Novitsky YM, Rosen MJ (2012) Modified hernia grading scale to stratify surgical site occurrence after open ventral hernia repairs. J Am Coll Surg 215(6):787-793

16. Blatnik JA, Krpata DM, Novitsky YW, Rosen MJ (2012) Does a history of wound infection predict postoperative surgical site infection after ventral hernia repair? Am J Surg 203(3):370-374

17. Krpata DM, Blatnik JA, Novitsky YW, Rosen MJ (2013) Evaluation of high-risk, comorbid patients undergoing open ventral hernia repair with synthetic mesh. Surgery 153(1):120-125

18. Choi JJ, Palaniappa NC, Dallas KB, Rudich TB, Colon MJ, Divino CM (2012) Use of mesh during ventral hernia repair in clean-contaminated and contaminated cases: outcomes of 33,832 cases. Ann Surg 255(1):176-180

19. Miserez M, Grass G, Weiss C, Stützer H, Sauerland S, Neugebauer EA (2010) Closure of the LAPSIS trial. Br J Surg 97(10): 1598

20. Bellows CF, Smith A, Malsbury J, Helton WS (2012) Repair of incisional hernias with biological prosthesis: a systematic review of current evidence. Am J Surg 205(1):85-101

21. Slater NJ, van der Kolk M, Hendriks T, van Goor H, Bleichrodt RP (2012) Biologic grafts for ventral hernia repair: a systematic review. Am J Surg. doi:10.1016/j.amjsurg.2012.05.028

22. Smart NJ, Marshall M, Daniels IR (2012) Biological meshes: a review of their use in abdominal wall hernia repairs. Surgeon 10(3):159-171

23. Primus F, Harris HW (2013) A critical review of biological mesh use in ventral hernia repairs under contaminated conditions. Hernia. doi:10.1007/s10029-012-1037-8

24. Itani KM, Rosen M, Vargo D, Awad SS, Denoto G III, Butler CE, RICH Study Group (2012) Prospective study of single-stage repair of contaminated hernias using a biologic porcine tissue matrix: the RICH Study. Surgery 152(3):498-505

25. Berrevoet F, Vanlander A, Saiz-Barriga M, Rogier X, Troisi R (2012) Infected large pore meshes may be salvaged by topical 
negative pressure therapy. Hernia. doi:10.1007/s10029-0120969-3

26. Bessa S, Raazek AA (2012) Results of prosthetic mesh repair in emergency management of the acutely incarcerated and/or strangulated ventral hernias: a seven years study. Hernia. doi: 10.1007/s10029-012-0938-x

27. Sauerland S, Walgenbach M, Habermalz B, Seiler CM, Miserez M (2011) Laparoscopic versus open surgical techniques for ventral or incisional hernia repair. Cochrane Database Syst Rev 16(3):CD007781. doi:10.1002/14651858.CD007781.pub2

28. Acosta S, Bjarnason T, Petersson U, Pålsson B, Wanhainen A, Svensson M, Djavani K, Björck M (2011) Multicentre prospective study of fascial closure rate after open abdomen with vacuum and mesh-mediated fascial traction. Br J Surg 98(5):735-743

29. Morris LM, LeBlanc KA (2012) Component separation technique utilizing an intraperitoneal biologic and an onlay lightweight polypropylene mesh: "a sandwich technique". Hernia. doi: 10.1007/s10029-012-0949-7

30. Espinosa-de-los-Monteros A, Dominguez I, Zamora-Valdés D, Castillo T, Fernández-Diaz O, Luna-Torres HA (2012) Closure of midline contaminated and recurrent incisional hernia with components separation technique reinforced with plication of the rectus muscles. Hernia. doi:10.1007/s10029-012-1012-4
31. Helgstrand F, Rosenberg J, Kehlet H, Strandfelt P, Bisgaard T (2012) Reoperation versus clinical recurrence rate after ventral hernia repair. Ann Surg 256(6):955-958

32. Ansaloni L, Catena F, Coccolini F, Negro P, Campanelli G, Miserez M (2009) New "biological" meshes: the need for a register. The EHS Registry for Biological Prostheses: call for participating European surgeons. Hernia 13(1):103-108

33. Coccolini F, Agresta F, Bassi A, Catena F, Crovella F, Ferrara R, Gossetti F, Marchi D, Munegato G, Negro P, Piccoli M, Melotti G, Sartelli M, di Visconte MS, Testini M, Bertoli P, Capponi MG, Lotti M, Manfredi R, Pisano M, Poiasina E, Poletti E, Luca A (2012) Italian Biological Prosthesis Work-Group (IBPWG): proposal for a decisional model in using biological prosthesis. World J Emerg Surg 7(1):34

34. Muysoms F, Campanelli G, Champault GG, DeBeaux AC, Dietz UA, Jeekel J, Klinge U, Köckerling F, Mandala V, Montgomery A, Morales Conde S, Puppe F, Simmermacher RK, Śmietański M, Miserez M (2012) EuraHS: the development of an international online platform for registration and outcome measurement of ventral abdominal wall hernia repair. Hernia 16(3):239-250 